\title{
Evaluation of Antimicrobial and Healing Activities of Frog Skin on Guinea Pigs Wounds
}

\author{
Mahere Rezazade Bazaz ${ }^{1}$; Mohammad Mashreghi ${ }^{2}$; Nasser Mahdavi Shahri ${ }^{1}$; Mansour \\ Mashreghi ${ }^{1, *} ;$ Ahmad Asoodeh $^{3}$; Morteza Behnam Rassouli ${ }^{1}$ \\ ${ }_{2}^{1}$ Department of Biology, Faculty of Sciences, Ferdowsi University of Mashhad, Mashhad, IR Iran \\ ${ }^{2}$ Nanotechnology Research Center, School of Pharmacy, Mashhad University of Medical Sciences, Mashhad, IR Iran \\ ${ }^{3}$ Department of Chemistry, Faculty of Sciences, Ferdowsi University of Mashhad, Mashhad, IR Iran \\ *Corresponding author: Mansour Mashreghi, Department of Biology, Faculty of Sciences, Ferdowsi University of Mashhad, Mashhad, IR Iran. Tel:+98-5138805513, Fax: +98-5138762227, \\ E-mail: mashrghi@um.ac.ir
}

Received: June 16, 2014; Revised: August 16, 2014; Accepted: August 29, 2014

\begin{abstract}
Background: Frog skin secretions have potentials against a wide spectrum of bacteria. Also, frog skin compositions have healing properties.

Objectives: The aim of this study was to investigate the antibacterial potentials along with healing properties of frog skin Rana ridibunda, a species which thoroughly lives in Iran marshes, as a biological dressing on wounds.

Materials and Methods: In this study, excisional wounds, dressed with frog skin, were compared between experimental and control groups of guinea pigs. In the experimental groups, wounds were dressed with the dermal (FS) and epidermal (RFS) sides of fresh frog $R$. ridibunda skin, while only usual cotton gauze covered the wounds of the control group. Furthermore, microbial samples were taken on different days ( $0,3,5$, and 7 days post injury) to count the number of the colony-forming units. Additionally, the microbial penetration test was performed on frog skin and then the progression of wound closure was evaluated.

Results: In the microbial studies, the bacterial load considerably declined in the wounds treated with FS and RFS compared with the control wounds. On day 7 post injury, the numbers of the colony-forming units for the FS, RFS, and control groups were 6.75, 105, and 375, respectively. In the penetration test, fresh frog skin showed to be a bacterial resistant dressing. The results revealed that the rate of wound closure in the experimental groups significantly was accelerated in comparison with that in the control group.

Conclusions: Our results demonstrated the antimicrobial properties of frog skin as a wound dressing, which has antimicrobial effects per se. This biological dressing shows promise as an effective biological wound dressing insofar as not only is it capable of resisting microbes and accelerating wound healing but also it is cost-effective and easy to use.
\end{abstract}

Keywords: Wound Infection; Biological Dressing; Rana ridibunda; Bacterial Barrier

\section{Background}

Human skin is always vulnerable to injury, which invariably leads to the loss of the integrity of the skin, exposure of the underside tissues to the invasion of microorganisms and corollary bacterial colonization, and even infection resulting in necrosis and tissue degeneration. Hence, the prevention of wound infection has always been a challenge. If wounds become contaminated with bacteria or clinically infected, wound healing is likely to be impaired (1). Among the microorganisms that infect non-surgical traumatic wounds in hospitals, Staphylococcus aureus is the most common and, as such, requires due attention to nosocomial infections and non-surgical wound infections (2). Ideal dressings for the prevention of skin injury infections should be able to act as a bacterial barrier and possess antimicrobial properties (3).

Folk medicine practitioners have always sought to introduce new wound healing agents. These agents include plant and animal products with special properties for the treatment of wounds and prevention of wound infection. Although the application of traditional medicine worldwide long time ago, some Asian and African countries still rely on their traditional medicine for their primary health-care needs (4). From the ancient time, medical usages of animals and their products were extended as cheap, fresh, and available remedies by the indigenous people of different cultures (5). In the modern era, some physicians still resort to the use of such remedies to cure their patients.

Wound healing, especially when a large part of the skin is lost, is an important challenge in medicine. Sometimes in the wound healing process, it is difficult to achieve a rapid and complete healing (6). Demands for biological wound dressings like skin and other organs of different animals such as porcine skin (7) and bovine amniotic membrane (8) are growing worldwide (9-11). Frog skin is one of these animal products which was used to treat

Copyright (C) 2015, Ahvaz Jundishapur University of Medical Sciences. This is an open-access article distributed under the terms of the Creative Commons Attribution-NonCommercial 4.0 International License (http://creativecommons.org/licenses/by-nc/4.0/) which permits copy and redistribute the material just in noncommercial usages, provided the original work is properly cited. 
wounds from the ancient time (3). In the last century, frog skin has been used as a biological coverage in some parts of the world such as Vietnam and South America $(3,12)$. Moreover, many researchers have extracted a variety of bioactive molecules with many biological activities from amphibian skin, including therapeutic properties such as, antimicrobial $(11,13)$, antiviral $(14,15)$, and anticancer (16).

The application of frog skin lipid extracts either topically or as an injection has anti-inflammatory and wound healing effects (17). It has also been shown that frog skin lipid extracts have a role in the proliferation and differentiation of keratinocytes and fibroblast cells (18). On the other hand, it was characterized that part of the healing potentials of frog skin is due to its collagen contents. A study on the application of frog skin collagen in cell cultures reported a rise in the proliferation and acceleration in the growth of keratinocyte and fibroblast cells (19). Secretions of frog skin glands constitute another invaluable source of components proven to be significantly effective in promoting the wound healing process; and also because of their antimicrobial properties, skin secretions could be used in treatment of wound infection $(20,21)$.

\section{Objectives}

The present study sought to investigate the healing and antibacterial efficacy of skin secretions of Rana ridibunda. We designed an investigation to study antibacterial and healing effects of fresh frog skin $R$. ridibunda as a biological dressing on full-thickness skin wounds of guinea pig. In this study, healing and antibacterial properties of frog skin were evaluated to make a comparison between dermal and epidermal sides. However, the capacity of fresh frog skin against the bacterial penetration also was evaluated. Rana ridibunda comes from the family Ranidae of the order Anura and the genus Rana or true frogs which thoroughly lives in Iran's marshes (22). Previously, we reported the efficacy of the pharmaceutical formulation of frog skin powder in promoting the wound healing process (23). However, in the present study, we investigated the differences between the healing and antimicrobial capacities of the FS and RFS of fresh frog skin.

\section{Materials and Methods}

\subsection{Experimental Animals}

The animal model in this study were male 6 - 8 months old guinea pigs $(n=18)$; weighted $700 \pm 50$ g, purchased from Razi Vaccine and Serum Research Institute, Mashhad, Iran. The animals were housed in a 12h:12h lightdark cycle in a temperature-controlled $\left(22 \pm 1^{\circ} \mathrm{C}\right)$ and standard animal house and fed with normal rodent diet and water ad libitum. Animals were randomly divided into the three groups $(n=6): 1)$ control group: animals were dressed with just cotton gauze, 2) frog skin group: animals were dressed with dermal side of the frog skin, hereafter referred to as FS, 3) reverse frog skin group: dressed with the RFS. Each animal was kept in a separate cage.

\subsection{Preparation of Frog Skin Dressings}

Frogs from $R$. ridibunda species were collected from the marshes of Khorasan Razavi Province in the northeast of Iran. After having been transferred to the lab, the frogs were washed with distilled water, maintained in proper conditions in accordance with the Amphibian Husbandry Resource Guide (24). Fresh dorsal skin of the euthanized frog $R$. ridibuna from the dermal and epidermal sides were used for FS and RFS used in the experimental groups, respectively, while the control group was dressed with just usual cotton gauze. Attempts were made to avoid the accidental movements of the biodressings on the wounds in the experimental groups by covering them with usual cotton gauze. Dressings were changed at 48 -hour intervals (25). All the experimental protocols were approved by the local institutional committee for animal ethics and were performed in accordance with the international rules on animal rights.

\subsection{Microbial Penetration Test}

Microbial penetration tests on the frog skins were performed using Staphylococcus aureus (PTCC 1431) and Escherichia coli (PTCC 1399) as typical Gram-positive and Gram-negative bacteria, respectively. In order to do this, cultures of these bacteria were added to the frog skins and the negative and positive controls were placed in the Tryptone Soya Bean Agar (TSA) (Quelab, Canada) plates. Then, the fresh frog skins as well as the negative and positive controls of commercial wound dressings were cultured in a TSA medium, which in advance was moistened with a sterile swap soaked in the Tryptone Soya Bean broth (TSB) (Quelab, Canada). There were two pieces of each dressing for each species of the bacteria. One drop of each mentioned bacterium obtained from an overnight culture in the TSB was placed on all the dressings, and the plates were incubated at $37^{\circ} \mathrm{C}$ for 72 hours. On the 3rd day of incubation, the frog skins and the control dressings were removed from the plates and were incubated at $37^{\circ} \mathrm{C}$ for another 3 days to study the growth of probable bacteria in the media (26). The negative control was a piece of intact commercial wound dressing (Hydrocolloid, Comfeel, Coloplast UK Ltd., Peterborough, UK) considered an absolute bacterial barrier, and the positive control was a piece of aseptically pierced commercial wound dressing.

\subsection{Wound Creation}

The dorsal hair in the thoracolumbar region of all the guinea pigs was removed with a shaver. Following the disinfection of the skin with $70 \%$ ethanol, four round fullthickness excisions, $4 \mathrm{~mm}$ in diameter, were made with a sterile dermal biopsy punch (Paramount Surgimed 
Ltd., New Delhi, India) on each side of the dorsal midline of the guinea pigs in a parallel manner. Each wound was at a 2-cm distance from the proximate wounds (27, 28). All the surgical procedures were performed under anesthesia induced with an intramuscular injection of ketamine $40 \mathrm{mg} / \mathrm{kg}$ (ketamine10\%, Alfasen, Woerden, Holland) and xylezine $5 \mathrm{mg} / \mathrm{kg}$ (xylezine 2\%, Alfasen, Woerden, The Netherlands) (29).

\subsection{Wound Microbial Studies}

The samples were taken aseptically from the wounds of all the groups on days 3, 5, and 7 post injury with sterile cotton swabs soaked in sterile Phosphate Buffer Saline (PBS) solution, followed by culturing in blood agar media (Quelab, Montreal, Quebec, Canada). After incubation at $37^{\circ} \mathrm{C}$ for 24 hours (26), the bacterial colonies, colonyforming units (CFUs) were counted for quantifying the effect of treatment on wounds contamination.

\subsection{Wound Closure Study}

Immediately, after creating the wounds and on days 3, 5 , and 7 post injury, photographs were taken from the wounds of all the groups, using a digital camera (PowerShot S2IS Canon; Canon Corp., Tokyo, Japan) at a straight defined distance vertically above the wounds $(2 \mathrm{~cm})$. The photographs were sent to the imaging analysis program, Image (NIH) software, to quantify the interest area for wound closure evaluation with respect to the original wound size (This software is accessible online at http:// rsbweb.nih.gov/ij/download.html.) (20). The number of the pixels in each wound area was calculated as the area of the wound, and the percentage of wound closure on each day (days 3, 5, and 7) was calculated according to the equation $1(20)$ :
(1) Precentage of wound closure da $y_{\mathrm{n}}=100-\left(\left[\frac{\text { Total wound area da } y_{\mathrm{n}}}{\text { Original wound area da } y_{0}}\right] \times 100\right)$

\subsection{Statistical Analysis}

For each parameter, the data are presented as mean \pm standard error of the mean (SEM) values. The One-Way Analysis of Variance was employed to analyze the percentage of wound closure and CFUs. The level of significance was set at a $\mathrm{P}<0.05$. The statistical analyses were performed using Statistical Package for the Social Sciences (SPSS) for Windows (SPSS 11.5, SPSS Inc., Chicago IL, USA).

\section{Results}

\subsection{Microbial Penetration}

In the penetration test, the cultures were checked 24 , 42 , and 72 hours after removing of dressings. The results showed no colony in the culture media under the intact dressings, including the fresh frog skin and the negative control. However, in the positive control, in which the culture medium was dressed with a mechanically pierced commercial wound dressing, the bacterial growth of both species was observed within three 24-hour intervals after removing the dressings (Table 1 ).

\subsection{Wound Microbial Load}

The ability of the dressings to control the microbial load of the wounds was evaluated. The CFUs of the wounds covered with the FS and RFS showed a significant decrease. The bacterial load considerably declined in the wounds treated with the FS and RFS on all the study days, compared with the wounds dressed with usual cotton gauze (Figure 1).

\begin{tabular}{|c|c|c|c|}
\hline Samples of Wound Dressing & 24 & 48 & 72 \\
\hline \multicolumn{4}{|l|}{ Fresh frog skin, test } \\
\hline Escherichia coli & - & - & - \\
\hline Staphylococcus aureus & - & - & - \\
\hline \multicolumn{4}{|l|}{$\begin{array}{l}\text { Commercial wound dress- } \\
\text { ing, negative control }\end{array}$} \\
\hline Escherichia coli & - & - & - \\
\hline Staphylococcus aureus & - & - & - \\
\hline \multicolumn{4}{|l|}{$\begin{array}{l}\text { Pierced commercial wound } \\
\text { dressing, positive control }\end{array}$} \\
\hline Escherichia coli & + & + & + \\
\hline Staphylococcus aureus & + & + & + \\
\hline
\end{tabular}




\subsection{Wound Closure}

The area of the wound measured with Image (NIH) software was considered as the percentage of wound closure and marked as one of the wound healing parameters during the study period. Our findings showed faster wound closure in response to the application of the FS and RFS. The results also showed a significant difference in the percentage of wound closure between the experimental and control groups on day 3. On day 5 post injury, the wounds treated with the RFS presented a significant reduction in wound area in comparison with the control group. The reduction in wound area was greater in the FS group, although the difference between the FS and control group was not statistically significant. On the 7th day of the study, the percentage of wound closure significantly increased in both RFS and FS compared with the control group. In the wounds treated with the FS and RFS, a similar contraction trend was observed; their differences, however, were not significant throughout the study period (Figure 2).

Figure 1. Number of the Colony Forming Unites (CFUs) in the Wound Cultures during the Study Days

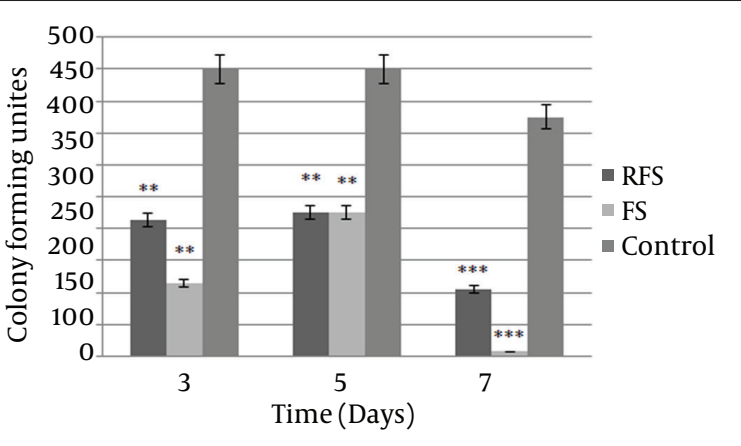

More than 450 CFUs were not counted. Data are presented as mean \pm SEM ${ }^{* *} \mathrm{P}<0.01,{ }^{* * *} \mathrm{P}<0.001$ compared with the control group, $\mathrm{FS}=$ frog skin, RFS $=$ reverse frog skin.

Figure 2. Percentage of Wound Closure on the Different Study Days

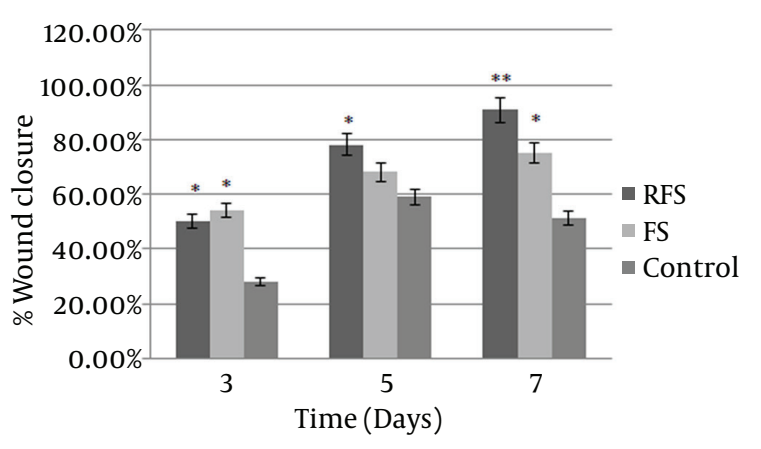

Totally, the FS had a significantly higher rate of increase in the percentage of wound closure than the rate in the control group. The data are presented as mean \pm SEM; ${ }^{*} \mathrm{P}<0.05,{ }^{* *} \mathrm{P}<0.01$ compared with the control group. $\mathrm{FS}=$ frog skin, RFS = reverse frog skin.

\section{Discussion}

In the present study, the efficacy of dermal and epidermal sides of the frog skin $R$. ridibunda, as wound dressings, was assessed in terms of wound microbial load and wound closure. The results showed that the $R$. ridibunda skin, from both dermal and epidermal sides were considerably effective in controlling the wound microbial load. Wounds, especially chronic wounds, lead to the continuous existence of bacteria and formation of organized biofilms. Biofilm-forming bacteria are notoriously difficult to culture and are more resistant to antimicrobial agents (30). However, the control wound bacteria to prevent biofilm formation appears to be necessary. Due to increasing resistance to antibiotics, it is essential to looking for antimicrobial agents which have potential against broad spectrum bacteria. Methicillin-resistant Staphylococcus aureus (MRSA) is one of the major bacteria causing wound infection. In one study, antimicrobial effects of Zataria multiflora extracts inhibited the growth of all the MRSA strains (31). In addition, because of increasing frequency of anti-microbial resistant isolates from nosocomial infections (32), emphasizes the necessity for another source of antimicrobial compounds. It was also shown that frog $R$. ridibunda skin secrestions have strong antimicrobial activity against MRSA (33). An ideal wound dressing should have both wound healing and antimicrobial properties, and previous research shows that frog skin possesses both properties.

Lipid compositions extracted from the skin of the genius Rana have anti-inflammatory properties $(17,18)$, reducing the inflammatory cells and promoting the wound healing process. Furthermore, the collagen and the lipid and peptide structures of frog skin have the ability to increase the proliferation and migration of endothelial cells in vitro and in vivo (18-20). These compositions also prompt an increase in the extracellular matrix proteins in the granulation tissue such as hydroxyproline and hexosamine, which is a sign of cellular proliferation in the wound site $(17,25)$. Furthermore, the secretions of frog skin glands are a source of components approved to have microbicide properties could be used in treatment of wound infection $(20,21)$.

In this study, CFU counts in each swabbed wound, regarded as contamination rate in wound site. CFU was significantly low in wounds dressed with FS and RFS, which confirmed the impressive effects of frog skin in decreasing the wound microbial load. These results have a precise agreement with other studies, in which $R$. ridibunda skin secretions showed extremely antimicrobial effects $(20,33)$. In comparison, FS and RFS, did not show any significant differences, which are demonstrated effectiveness of both FS and RFS in declining the bacterial load in the wound site.

A proper and ideal wound dressing should protect the wound against bacteria and pathogens (34). In the bacterial penetration study, typical Gram-positive and nega- 
Rezazade Bazaz M et al.

tive bacteria were used to test the impenetrability of frog skin against bacterial agents. The observations suggested that frog skin was an absolute bacterial barrier against the penetration of bacteria.

Few hours after injury, reconstruction of epithelium was begun and around 1 or 2 days later, epithelial cells migrated from wounds margin, multiply and make a thick layer of cells. In the process of reepithelization, proliferated keratinocytes migrate to the edges of the wound, and cell migration through the wound edges continues until wound would be closed (35). In the present study, R. ridibunda skin, was effective on faster wound closure especially in wounds were covered with FS; most likely because of lipid and collagen compositions that locate in dermal side of frog skin $(17,19)$. Our results showed that rate of wound closure in the experimental wounds were significantly faster than control wounds and also wounds with higher collagen density showed acceleration in wound contraction. This is supported by other studies indicating the positive effects of collagen and lipids structures from frog skin $R$. tigerina on the migration and proliferation of epithelial cells (17, 19). Moreover, the compositions of the secretions of frog skin glands probably activate the cell migration and reepithelization process $(14,20)$.

The present study showed that $R$. ridibunda skin, as a wound dressing, had antibacterial effects and provided an impenetrable barrier against bacteria. Moreover, this wound dressing exhibited healing and regenerative characteristics, making it significantly effective in wound closure. Furthermore, there were no significant differences between the FS and RFS, denoting that both sides of $R$. ridibunda skin possessed these positive effects on the wound healing process. In this study frog skin $R$. ridibunda demonstrated potentials as biological dressing because it able to resist microbes, cost efficient, effectiveness in healing, easy to prepare and use.

\section{Acknowledgements}

We are grateful to Ferdowsi University of Mashhad Research Council for their financial support of this work (Grant: P35:24-01-89).

\section{Authors' Contributions}

Experimental design and work: Mahere Rezazade Bazaz and Mohammad Mashreghi; work supervisions and consultants: Nasser Mahdavi Shahri, Mansour Mashreghi, Ahmad Asoodeh, and Morteza Behnam Rasouli.

\section{References}

1. Duerden BI. Virulence factors in anaerobes. Clin Infect Dis. 1994;18 Suppl 4:S253-9.

2. Noroozi H, Kazemi A, Fadaee R, Alavi S, Mohammadzadeh M. Microbiologic assessment of non-surgical traumatic wound infections and surgical site infections in hospitalized patients. Arch Clin Infect Dis. 2010;5(2):80-3.

3. Shores JT, Gabriel A, Gupta S. Skin substitutes and alternatives: a review. Adv Skin Wound Care. 2007;20(9 Pt 1):493-508.
4. Dorai AA. Wound care with traditional, complementary and alternative medicine. Indian J Plast Surg. 2012;45(2):418-24.

5. Angeletti LR, Agrimi U, French D, Curia C, Mariani-Costantini R. Healing rituals and sacred serpents. Lancet.1992;340(8813):223-5.

6. Limova M. Active wound coverings: bioengineered skin and dermal substitutes. Surg Clin North Am. 2010;90(6):1237-55.

7. Ersek RA, Hachen HJ. Porcine Xenografts in the Treatment of Pressure Ulcers. Ann Plastic Surg. 1980;5(6):464-70.

8. Lo V, Pope E. Amniotic membrane use in dermatology. Int J Dermatol. 2009;48(9):935-40.

9. Ehrenreich M, Ruszczak Z. Update on tissue-engineered biological dressings. Tissue Eng. 2006;12(9):2407-24.

10. Chiu T, Burd A. "Xenograft" dressing in the treatment of burns. Clin Dermatol. 2005;23(4):419-23.

11. Chern PL, Baum CL, Arpey CJ. Biologic dressings: current applications and limitations in dermatologic surgery. Dermatol Surg. 2009;35(6):891-906.

12. Sarto Piccolo N, Sarto Piccolo M, Sarto Piccolo MT. The Use of Frogskin as a Biological Dressing for Temporary Cover of Burn Wounds. Plast Aesth Surg. 2008:129-37.

13. Zasloff M. Magainins, a class of antimicrobial peptides from Xenopus skin: isolation, characterization of two active forms, and partial cDNA sequence of a precursor. Proc Natl Acad Sci U S A. 1987;84(15):5449-53.

14. Yu WR, Liu T, Kiehl TR, Fehlings MG. Human neuropathological and animal model evidence supporting a role for Fas-mediated apoptosis and inflammation in cervical spondylotic myelopathy. Brain. 2011;134(Pt 5):1277-92.

15. Papini R. Management of burn injuries of various depths. BMJ. 2004;329(7458):158-60.

16. Ghavami S, Asoodeh A, Klonisch T, Halayko AJ, Kadkhoda K, Kroczak TJ, et al. Brevinin-2R(1) semi-selectively kills cancer cells by a distinct mechanism, which involves the lysosomal-mitochondrial death pathway. J Cell Mol Med.2008;12(3):1005-22.

17. Raghavan KV, Babu M, Rajaram R, Purna Sai K. Efficacy of frog skin lipids in wound healing. Lipids Health Dis. 2010;9:74.

18. Sai KP, Babu M. Growth potential of Rana tigerina skin lipids in cell cultures. In Vitro Cell Dev Biol Anim. 1998;34(7):561-7.

19. Kumar KV, Sai KP, Babu M. Application of frog (Rana tigerina Daudin) skin collagen as a novel substrate in cell culture. $J$ Biomed Mater Res. 2002;61(2):197-202.

20. Mashreghi M, Rezazade Bazaz M, Mahdavi Shahri N, Asoodeh A, Mashreghi M, Behnam Rassouli M, et al. Topical effects of frog "Rana ridibunda" skin secretions on wound healing and reduction of wound microbial load. J Ethnopharmacol. 2013; 145(3):793-7.

21. Asoodeh A, Naderi-Manesh H, Mirshahi M, Ranjbar B. Purification and characterization of an antibacterial, antifungal and non hemolytic peptide from Rana Ridibunda. J sci IRI. 2004;15(4):303-9.

22. Baloutch M, Kami HG. Amphibians of Iran.Tehran, Iran: Tehran University Publisher; 1995.

23. Rezazade Bazaz M, Mashreghi M, Mahdavi Shahri N, Mashreghi M, Asoodeh A, Behnam Rassouli M, et al. Pharmaceutical application of frog skin on full-thickness skin wound healing in mice. Pharm Biol. 2013;51(12):1600-6.

24. Poole VA, Grow S. Amphibian Husbandry Resource Guide. 1.1 editor. San Diego, CA, USA: AZA's Amphibi Taxon Advis; 2008

25. Sai KP, Reddy PN, Babu M. Investigations on wound healing by using amphibian skin. Indian J Exp Biol. 1995;33(9):673-6.

26. Park M, Kim S, Kim IS, Son D. Healing of a porcine burn wound dressed with human and bovine amniotic membranes. Wound Repair Regen. 2008;16(4):520-8.

27. Gal P, Kilik R, Mokry M, Vidinsky B, Vasilenko T, Mozes S, et al. Simple method of open skin wound healing model in corticosteroid-treated and diabetic rats: standardization of semi-quantitative and quantitative histological assessments. Veterinarni Med. 2008;53(12):652-9.

28. Paddock HN, Schultz GS, Mast BA. Methods in reepithelialization A porcine model of partial-thickness wounds. Methods Mol Med. 2003;78:17-36.

29. White SR. Wound Healing in Airways In Vivo. Methods Mol Med. 2003;78:121-32 
Rezazade Bazaz M et al.

30. Stewart PS, William Costerton J. Antibiotic resistance of bacteria in biofilms. Lancet. 2001;358(9276):135-8.

31. Motevasel M, Okhovat MA, Zomorodian K, Farshad S. A Study of the Effect of Zataria multiflora Extract on Methicillin Resistant Staphylococcus aureus. Jundishapur J Microbiol. 2013;6(5)

32. Oskouie SA, Rezaie MA, Panahi F, Firoozi F, Haghi ME, Panahi F. Microbiological Evaluation of Nosocomial Infections by Using National Nosocomial Infection Surveillance (NNIS) System. Arch Ped Infect Dis. 2014;2(2):217-24.
33. Asoodeh A, Zardini HZ, Chamani J. Identification and characterization of two novel antimicrobial peptides, temporin-Ra and temporin-Rb, from skin secretions of the marsh frog (Rana ridibunda). J Peptide Sci. 2012;18(1):10-6.

34. Singh R, Chacharkar MP, Mathur AK. Chitin membrane for wound dressing application-preparation, characterisation and toxicological evaluation. Int Wound J. 2008;5(5):665-73.

35. Baum CL, Arpey CJ. Normal Cutaneous Wound Healing. Dermatol Surg. 2005;31(6):674-86. 